\title{
CYTOLOGIC STUDIES ON RHEUMATIC FEVER
}

\author{
II. Cells of Rheumatic Exudates \\ BY CURRIER MCEWEN \\ (From the Hospital of the Rockefeller Institute for Medical Research and the Department of \\ Medicine, University and Bellerue Hospital Medical College, New York \\ University, New York City)
}

(Received for publication October 8, 1934)

Previously (1), it was shown that rheumatic granulomata are typified by cells which have a characteristic appearance when stained supravitally with neutral red and Janus green (2), and which differ, in their reaction to these dyes, from the typical cells of tuberculous and experimental syphilitic granulomata. The purpose of the present study was to investigate similarly the cells of rheumatic exudates, and to compare the cytologic characteristics with certain clinical features of the disease. It was further proposed to learn whether cells like those of rheumatic granulomata might be found in these exudates and thus serve as a diagnostic aid in questionable cases.

Forkner, Shands and Poston (3) and Forkner (4) have reviewed the work done upon the cytologic aspects of synovial fluid prior to the introduction of methods for supravital staining, and have indicated the uncertainty which exists concerning the nature of cells described in those studies because of the limitations of the methods used. Key (5) employed supravital staining in examining cells of synovial fluid of normal rabbits; and similar studies were made on synovial fluid of normal cattle by Bauer and his co-workers (6). Key (7) likewise has described the cells in experimentally induced arthritis of rabbits; and Forkner, Shands and Poston (3) and Shands (8), employed the same technique in studying the synovial fluid in human chronic arthritis. No reports of comparable investigations in rheumatic fever are available.

\section{MATERIAL AND TECHNIQUE}

Sixty-two arthritic, 8 pleural and 5 pericardial exudates from 33 patients with rheumatic fever were compared with 35 similar exudates from patients with other diseases; 3 fluids from the joints of patients with cardiac edema and 2 from supposedly normal joints were also studied. (See Tables I and III for data on synovial exudates.)
Fluids were aspirated aseptically under novocaine anesthesia. All synovial exudates were obtained from knee joints prior to antirheumatic medication; and, in order to estimate the amount present, all obtainable fluid was removed.

Record was made of the total amount and character of the fluid, of the total number of white cells per c.mm., and of the differential counts made upon living and fixed cells. In some instances, the fluid was centrifuged and the sedimented masses of cells were fixed, imbedded in paraffin and examined in ordinary microscopic sections.

Fixed films of aspirated fluids were stained by several methods, the most satisfactory of which was a modification of the malachite green-acridine red stain of Hitchcock and Ehrich (9). As soon as dry, the films were fixed in Zenker-acetic solution for 2 minutes, washed in running water for 10 minutes, immersed in the mixed stain solution for about 30 seconds, rinsed very quickly first in water and then in absolute alcohol, and finally passed to xylol and balsam. With this method, the cells were never obscured by deeply colored debris as they often were in films stained with eosin-methylene blue and by Wright's and other methods.

The supravitally stained cells were examined in a warm-box at $37^{\circ} \mathrm{C}$. within 30 minutes of aspiration. Drops of fluid were placed upon cover slips which were then inverted upon slides covered with a dry film of neutral red and Janus green. The details of the method are given elsewhere $(1,10)$.

It was possible to record the differential counts in three ways: (1) in terms of percentages of the various cell types, (2) as the number of each type per c.mm., or (3) as the approximate total number of each type contained within the individual joint cavities. The latter method was chiefly employed.

\section{RESULTS}

Cytologic changes in the fluid of a single joint during the course of rheumatic polyarthritis

An attempt was made to follow the cytologic changes in the fluid of a single rheumatic joint as the inflammation progressed and receded. To this end, samples of synovial fluid were obtained, at intervals of one to four days, from the knee joints of two patients (P. G. and J. Si., Table I). 
TABLE I

Summary of data for synovial fluid from pationts with rheumatic fever-only specimens from joints uncomplicated by previous aspiration are listed

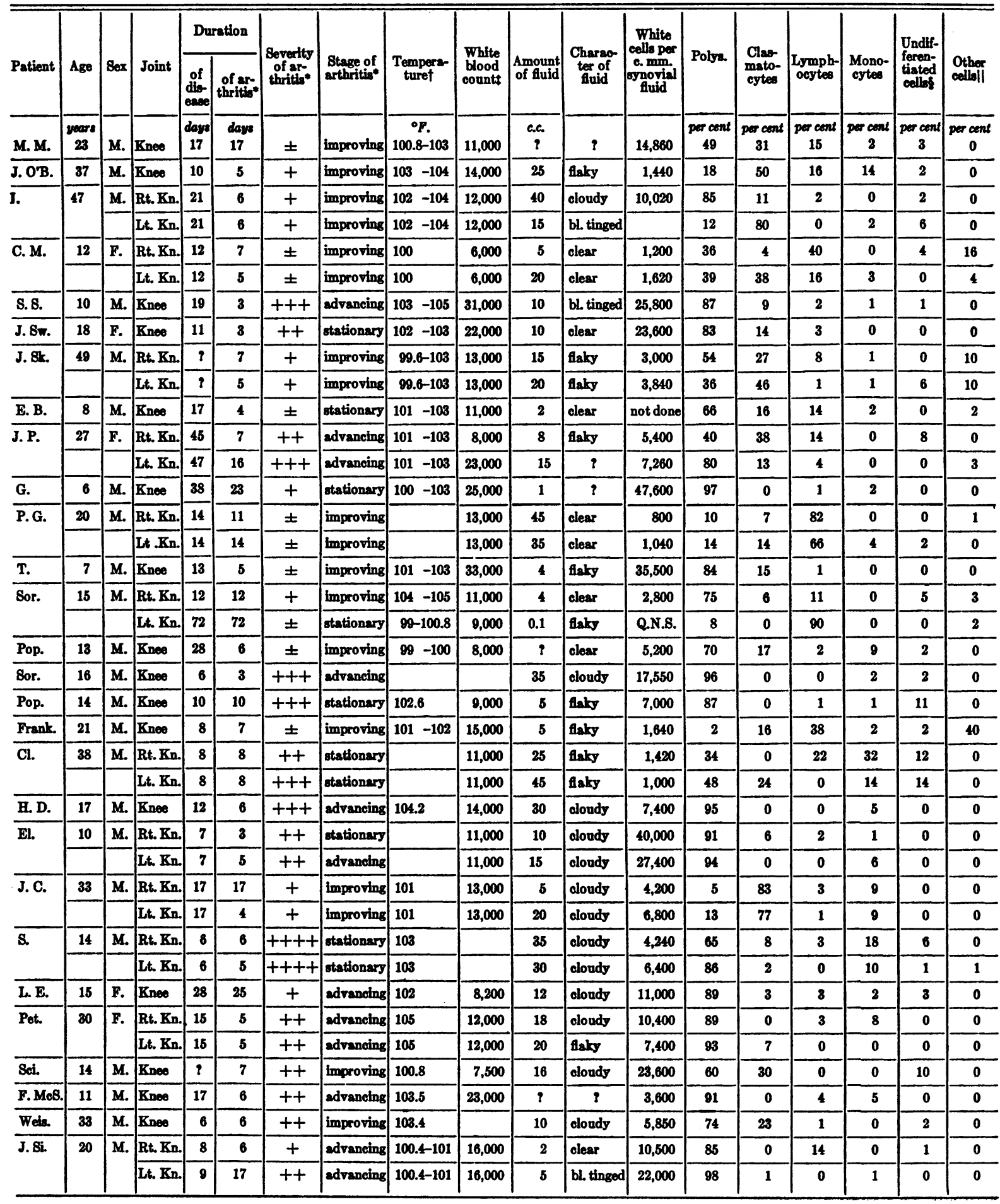

- of the partioular joint aspirated

figurea show temperature at time of asplration or give range during 24 hours before and after aspiration.

on day of acpiration

designates undifferentiated young connective tissue cells

Ilinoludes degenersted and unclascified cells 
From study of these, however, it was not possible to draw conclusions regarding the natural course of disease in the joints after the first aspiration, because the simple act of inserting an aspirating needle into the joint cavity was usually followed, twelve to twenty-four hours later, by pronounced changes.
Figures from one case are shown graphically in Figure 1, in which the curves indicate the number of each type of cell contained in $1 \mathrm{c.mm}$. of fluid, and in which the total amount of synovial fluid obtained at each aspiration is also recorded. As can be seen, in all but one instance, aspirations done at intervals of twenty-four to forty-eight hours

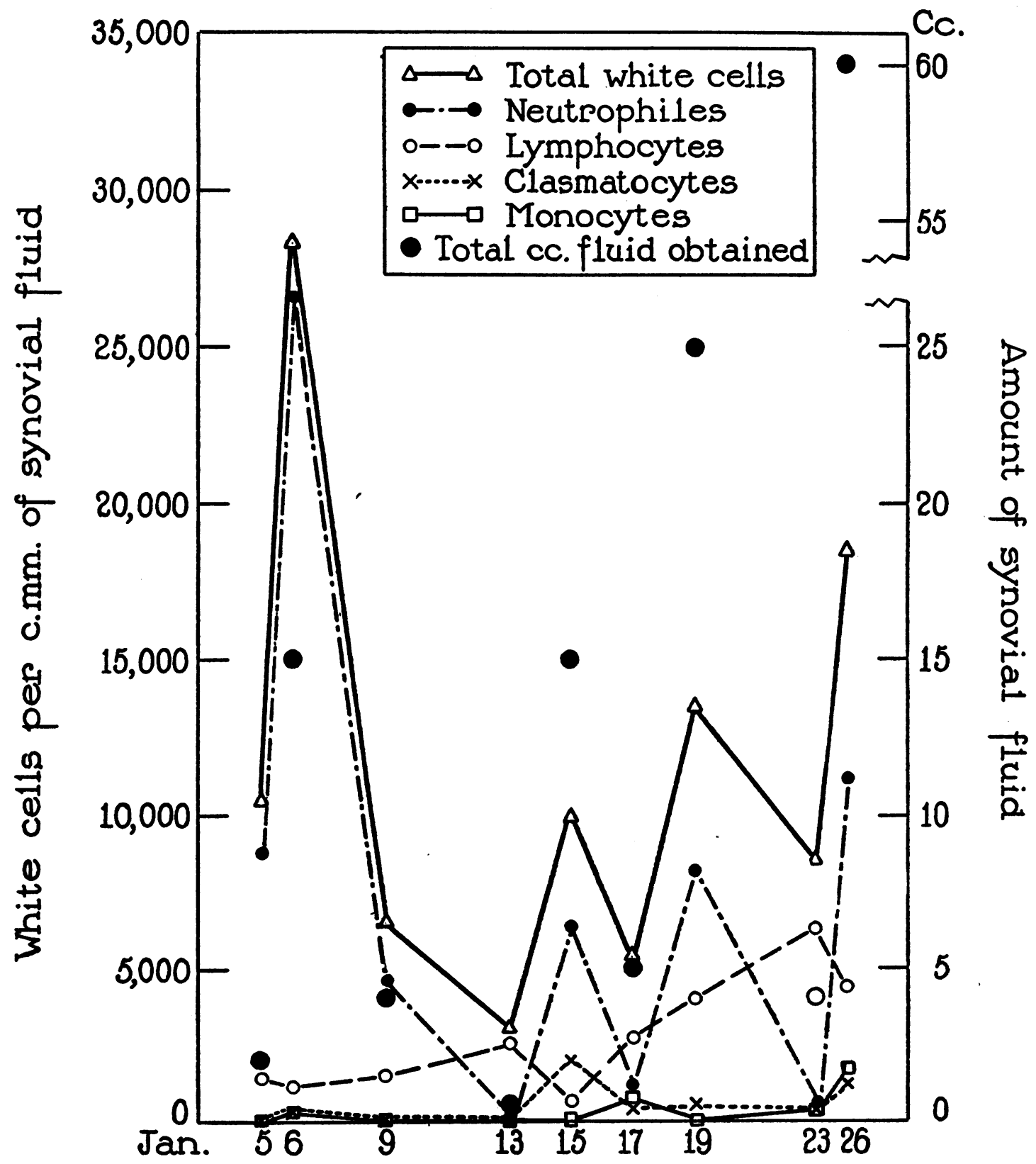

Fig. 1. Patient J. Si.

Number of various types of white cells per c.mm. of synovial fluid and amount of fluid obtained at successive aspirations of right knee joint. 
revealed a marked increase in the amount of synovial fluid and in the number of cells per cubic centimeter following the previous tap; after longer intervals, however, this was not the case. Similarly, in other patients, joints aspirated only once were often more swollen on the day following paracentesis, but this swelling subsided to the previous level after 3 or 4 days. Certainly the effects were merely temporary; it seems probable, nevertheless, that data obtained from frequent punctures of a single joint do not give a true picture of the naturally occurring changes. In order, therefore, to determine how the arthritis at any given stage might be reflected in the character of the synovial exudate, it was necessary to construct an average picture from data obtained from single observations on a number of joints.

\section{Amount and character of synovial fluid from pa- tients with rheumatic fever}

The amount of fluid obtained at thirty-seven aspirations uncomplicated by previous puncture, varied from a few drops to $45 \mathrm{cc}$., with an average of $14 \mathrm{cc}$.

The amounts were compared by means of graphs with the severity of the attack of rheumatic fever considered as a whole, the degree and duration of involvement of the particular joint aspirated, and the stage of arthritis in that joint, i.e., whether improving, remaining stationary or becoming more severe. Figure 2 indicates how slight was the correlation between severity of arthritis and volume of fluid, ${ }^{1}$ although some correspondence was to be expected since swelling was one of the criteria used for estimating the intensity of joint involvement. None of the other clinical features enumerated above had even this slight correlation with amount of synovial fluid.

The color of the fluid was always pale yellow. Among 33 specimens from 24 patients, 9 were clear, 13 were cloudy and 11 , in addition to being cloudy, contained macroscopic flakes. Clear

1 In Figures 2 and 4 the symbol \pm designates joints presenting very slight pain, tenderness, stiffness or swelling and also a few joints containing even a large amount of exudate (Figure 2) but showing no other signs of inflammation. Joints designated ++++ were markedly painful, tender, hot, red and swollen. The symbols + , ++ and +++ designate degrees of arthritis between the two extremes.

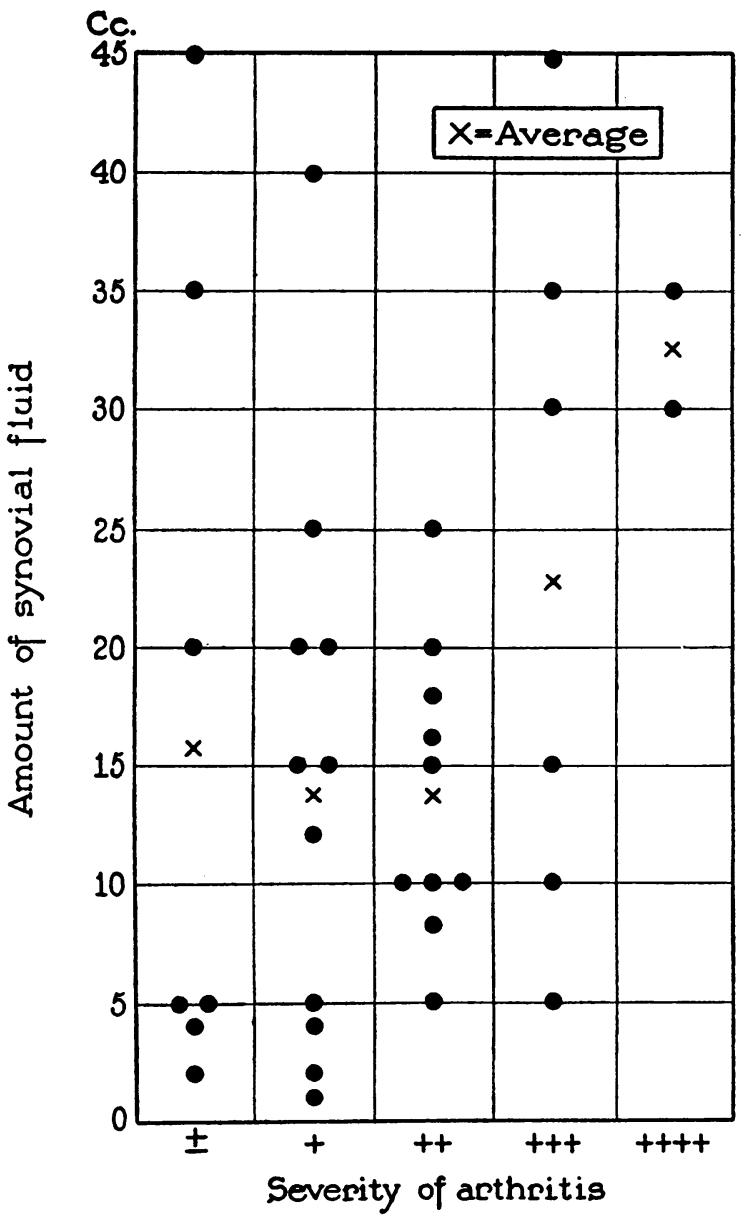

Fig. 2. Comparison of Amount of Synovial Fluid and Severity of Arthritis.

For meaning of \pm to ++++ see footnote, page .

fluid was never obtained from an intensely inflamed joint, but aside from this there was no obvious relationship between severity of arthritis and gross character of the synovial fluid. Furthermore, the latter appeared to correspond in no way with the duration or stage of arthritis, or the amount of effusion.

Although the degree of cloudiness was not infrequently quite marked, and the total white count in several rheumatic exudates above 40,000 per c.mm., in no instance was the fluid sufficiently turbid to have the appearance of pus. Exudate from a non-rheumatic joint infected with hemolytic streptococci, on the other hand, was distinctly purulent, although the total white cell count was only 29,000 per c.mm. 
Total white cell content of rheumatic synovial exudates

The total number of white cells per c.mm. of synovial fluid varied between 800 and 47,600 with an average of 10,750 . The frequency distribution is shown in Table II. The total number of

TABLE II

Distribution of total white cell counts obtained in thirtyseven exudates from rheumatic knee joints uncomplicated by previous aspiration

\begin{tabular}{|c|c|c|}
\hline \multicolumn{2}{|c|}{$\begin{array}{l}\text { Total white cells } \\
\text { per c.mm. }\end{array}$} & $\begin{array}{l}\text { Number of } \\
\text { exudates }\end{array}$ \\
\hline Under & 1000 & $\ldots 1$ \\
\hline 1000 to & 5000 & 13 \\
\hline $5000 "$ & 10000 & ......... \\
\hline 10000 & 15000 & ....... \\
\hline $15000 "$ & 20 & $\ldots \ldots \ldots$ \\
\hline 20000 " & 00 & $\ldots \ldots \ldots$ \\
\hline $\begin{array}{l}25000 \text { “ } \\
30000 \text { “ }\end{array}$ & $\begin{array}{l}30000 \\
35000\end{array}$ & $\cdots \cdots \cdots \cdots$ \\
\hline 0 & 40 & ....... \\
\hline bove & 40000 & $\ldots \ldots$ \\
\hline
\end{tabular}

white cells contained within individual knee joints was estimated to vary between 60,000 and 6,143 ,000 with an average of $1,447,000$.

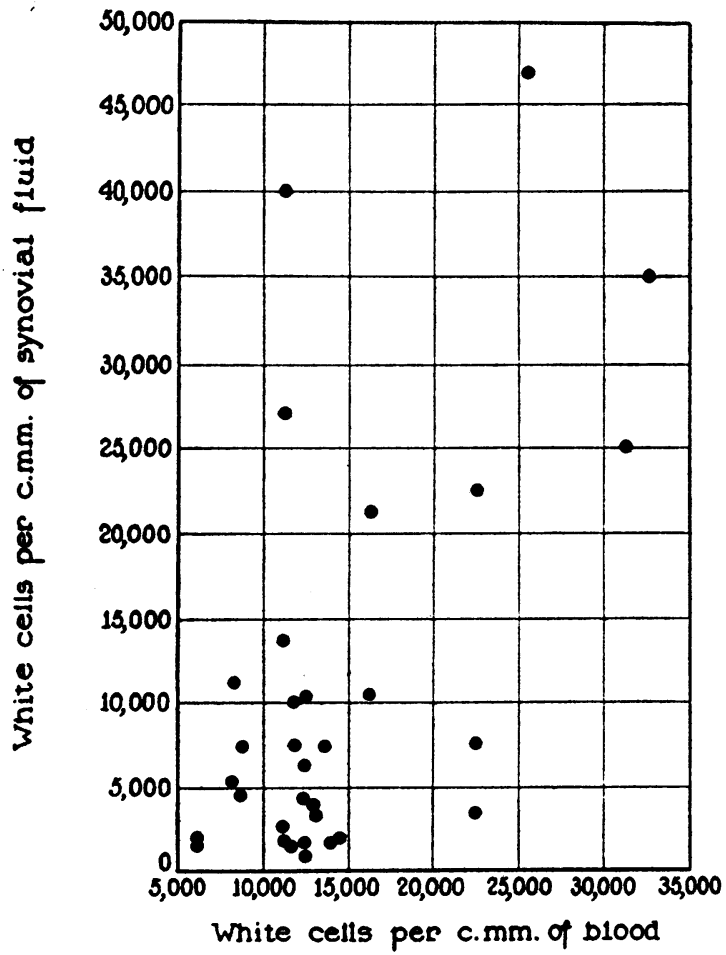

Fig. 3. Comparison of Number of White Cells per C.mm. of Blood and Synovial Fluid of Individual Patients.
In the same patients, the white cells in the blood varied between 6,000 and 33,000 with an average of 15,800 per c.mm., each blood count having been done on the same day as the corresponding count on synovial fluid. Figure 3, in which these two features are compared, suggests, perhaps, a slight tendency for them to vary directly.

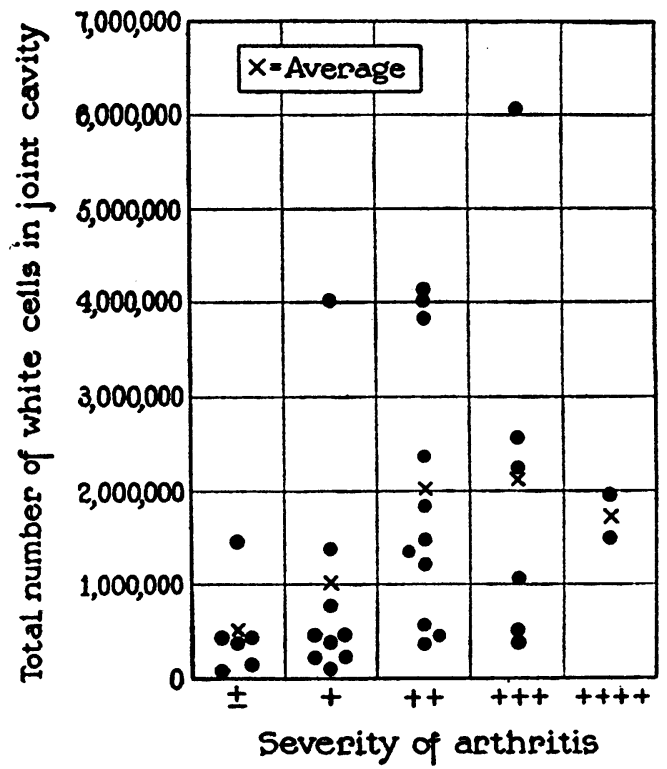

Fig. 4. Relation of Estimated Total Number of White Cells in Joint Cavity to Severity of ArTHRITIS.

Figure 4 indicates the relationship between the estimated total white cell content of the synovial fluids and the degree of inflammation of the individual joints. While some of those more severely involved contained relatively few cells, there was a slight correlation. This tendency was even less apparent when the number of cells per c.mm. was considered instead of the total cellular content.

In Figure $\mathbf{5}$ is shown the relation between the total number of white cells estimated to have been in the joint cavities and the stage of inflammation in those joints. While no exact correspondence between the two was found, the averages indicate a tendency for increasing arthritis to be accompanied by higher cellular content per joint.

Figure 6 records the relationship between the total number of white cells within individual joint cavities and the duration and stage of arthritis in the same joints. Involvement under 7 days tended to be associated with higher counts, but 


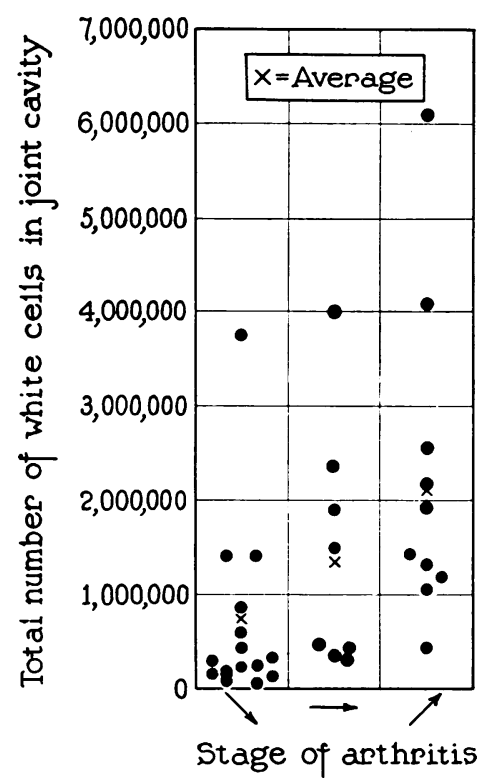

Fig. 5. Relation of Estimated Total Number of White Cells in Joint Cavity to Stage of ArthriTIS.

$$
\begin{aligned}
& \searrow=\text { arthritis } \\
& \rightarrow=\quad “ \quad \text { stationary. } \\
& \nearrow=\cdots \quad \text { becoming worse. }
\end{aligned}
$$

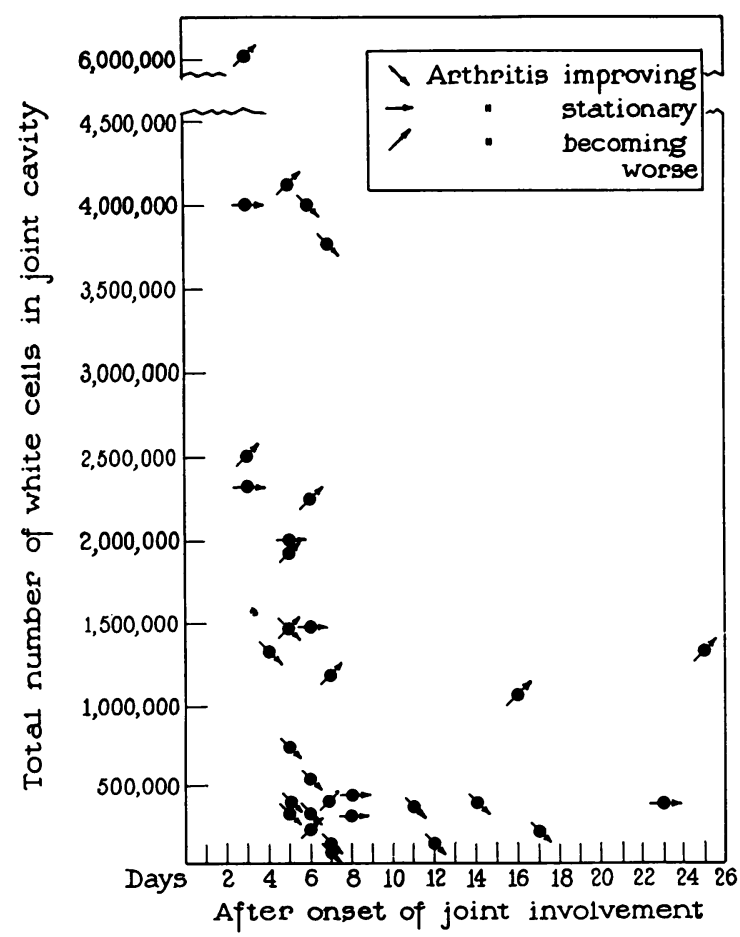

Fig. 6. Estimated Total White Cell Content of Joints Compared with Duration and Stage of ARTHRITIS. in the small number of joints aspirated for the first time after more prolonged arthritis, the relationship was vague. As was to be expected, the stage of arthritis in the individual joints had more bearing upon the total cellular content than had the duration, and it should be noted that the relatively high counts obtained after 16 and 25 days of arthritis were from joints which had suffered relapses and were increasing in severity of involvement at the time of aspiration.

\section{Differential formulas of white cells in rheumatic synovial exudates}

In the following discussion, the large mononuclear cells have been divided into monocytes and clasmatocytes according to the classification of Sabin, Doan and Cunningham (11).

Fixed, stained films of synovial fluid from patients with rheumatic fever showed large mononuclear cells, polymorphonuclear leukocytes in various stages of degeneration, and lymphocytes. Some of the large mononuclear cells were so filled with vacuoles and phagocytosed material as to leave little doubt that they were clasmatocytes; the majority, on the other hand, could not be accurately classified in the fixed preparations.

Cells of the type shown in Figure 7 were encountered frequently and, at first, proved difficult to classify. When stained by Wright's method

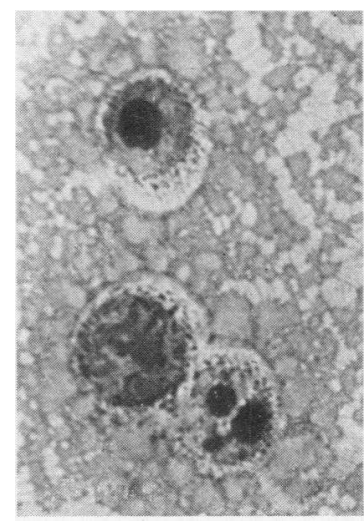

Fig. 7. Microphotograph of Polymorphonuclear Neutrophiles in Synovial Fluid.

Middle cell is normal; that at right shows nucleus becoming rounded-up and compact; that above shows more advanced degenerative changes with a single nuclear mass. The apparent granules in the two degenerated cells are artifacts caused by deposit of coagulated material from the synovial fluid. Wright's stain. $\times 1000$. 


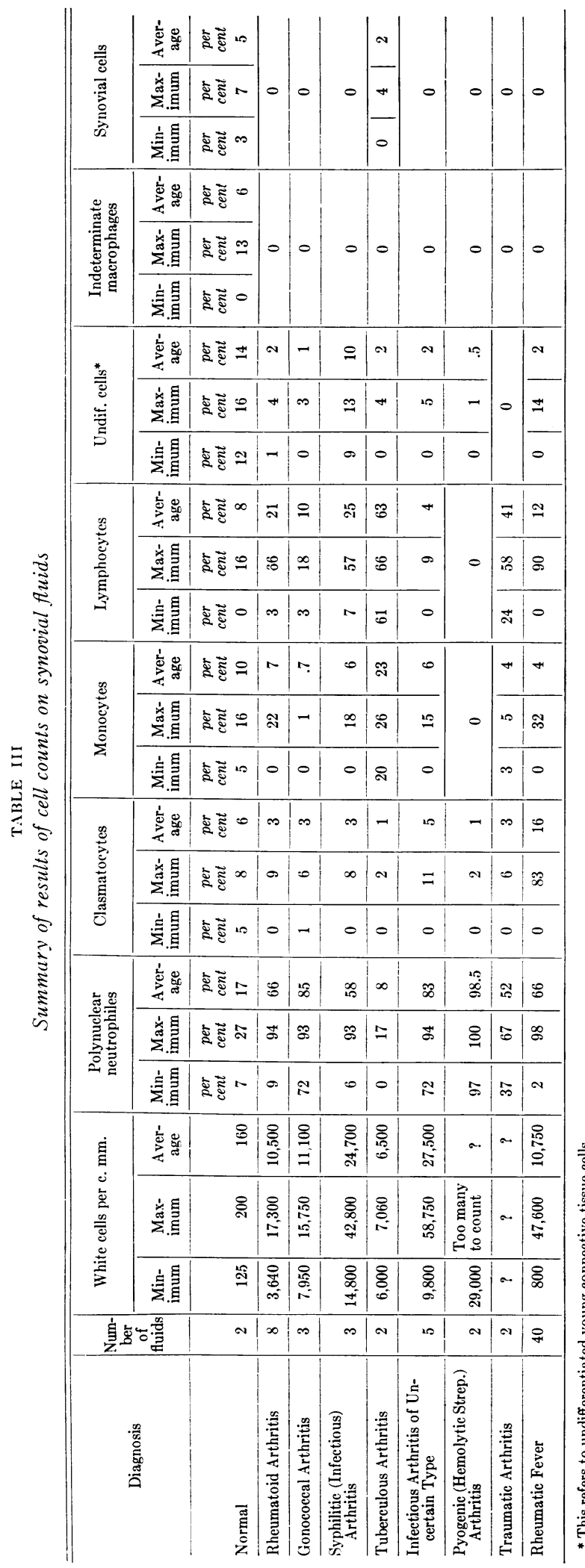


they were round and of the size of small or intermediate lymphocytes; the pink-stained cytoplasm presented a faintly stippled appearance but no granules; and the dark blue nuclei were round and pyknotic. When stained with malachite green and acridine red (9) they showed almost colorless cytoplasm and dark green nuclei. Their nature became clear when further study revealed all gradations between them and normal polymorphonuclear neutrophiles (Figure 7); and comparison of fixed films and supravitally stained preparations confirmed the belief that they were merely rounded-up, degenerated neutrophiles. It is probable that they have been mistaken for nucleated red cells, and their presence in exudate from a traumatized joint might lead, therefore, to an erroneous diagnosis of intracapsular fracture (12).

With supravital staining it was possible to classify most of the indefinite group of large mononuclear cells of the fixed preparations, into clasmatocytes and monocytes. The characteristics of all types of cells of synovial fluid have been amply described by Key $(5,7,15)$, Forkner, Shands and Poston (3), Bauer and his co-workers (6), and others; and hence they will not be discussed here. In addition to polymorphonuclear neutrophiles, lymphocytes, clasmatocytes and monocytes there was a moderate number of cells of the same general character as the latter but smaller and containing only a few small, scattered neutral red bodies and few or no mitochondria. These were interpreted by Dr. Florence R. Sabin as undifferentiated young connective tissue cells beginning to develop into either monocytes or clasmatocytes but not yet having progressed far enough to permit of definite identification. The minimum, maximum and average figures for all these cells in a series of 40 exudates from rheumatic knee joints are shown on the bottom line of Table III. Four of the specimens contained, in addition, 1 to 2 per cent of eosinophiles. The indeterminate macrophages of Key (5) were not found in fluids from inflamed joints. In every sample occasional erythrocytes were encountered, but, whenever numerous, their presence was attributed to trauma of aspiration.

Small masses of cells were numerous in all flaky fluids and, in every instance in which identification was possible, the cells composing them were clasmatocytes and polymorphonuclear leuko- cytes. In two fluids, small masses were seen which were perhaps composed of synovial lining cells, although the clumps were too thick for exact identification of individual elements. In none of the samples of synovial fluid from inflamed joints were isolated synovial lining cells identified.

An important relationship appeared to exist between the differential formulas and (1) the stage of arthritis, and (2) the age of the patient. In Figure 8 are plotted the differential counts for the individual joints in which arthritis was becoming worse, remaining unchanged, and improving; and these data, as well as the averages, are recorded separately for patients under and over twenty years of age. The age of twenty was chosen arbitrarily as the dividing line between the younger and older groups. Although the number of specimens in each category is too small for statistical analysis, and the spread of percentages in several of the categories is considerable; nevertheless, the trends shown by the distribution of individual counts and the averages for the various categories appear definite enough to be significant. With increasing arthritis there was a great predominance of polymorphonuclear neutrophiles and few clasmatocytes. With improvement, on the other hand, the percentage of clasmatocytes increased. Furthermore, the specimens from patients in the younger age group contained a higher ratio of polymorphonuclears to clasmatocytes than did those from older patients. Thus, the age of the patient and stage of arthritis appeared to have sufficient relationship to the cellular reaction in the synovial exudate to make difficult the interpretation of findings in any given specimen unless these two factors were taken into consideration. For example, the polymorphonuclear neutrophiles in synovial fluids from patients under twenty years of age whose arthritis was increasing, averaged 92 per cent of the white cells present; while in the fluids from improving joints of older patients, the polymorphonuclears averaged only 31 per cent, but the clasmatocytes 39 per cent. The figures for the lymphocytes tended to parallel those for the clasmatocytes. On the other hand, no such correlation was evidenced by the monocytes and undifferentiated young connective tissue cells, which were present in all fluids in approximately equal numbers. While the cytologic differences in the three stages of arthritis were not 


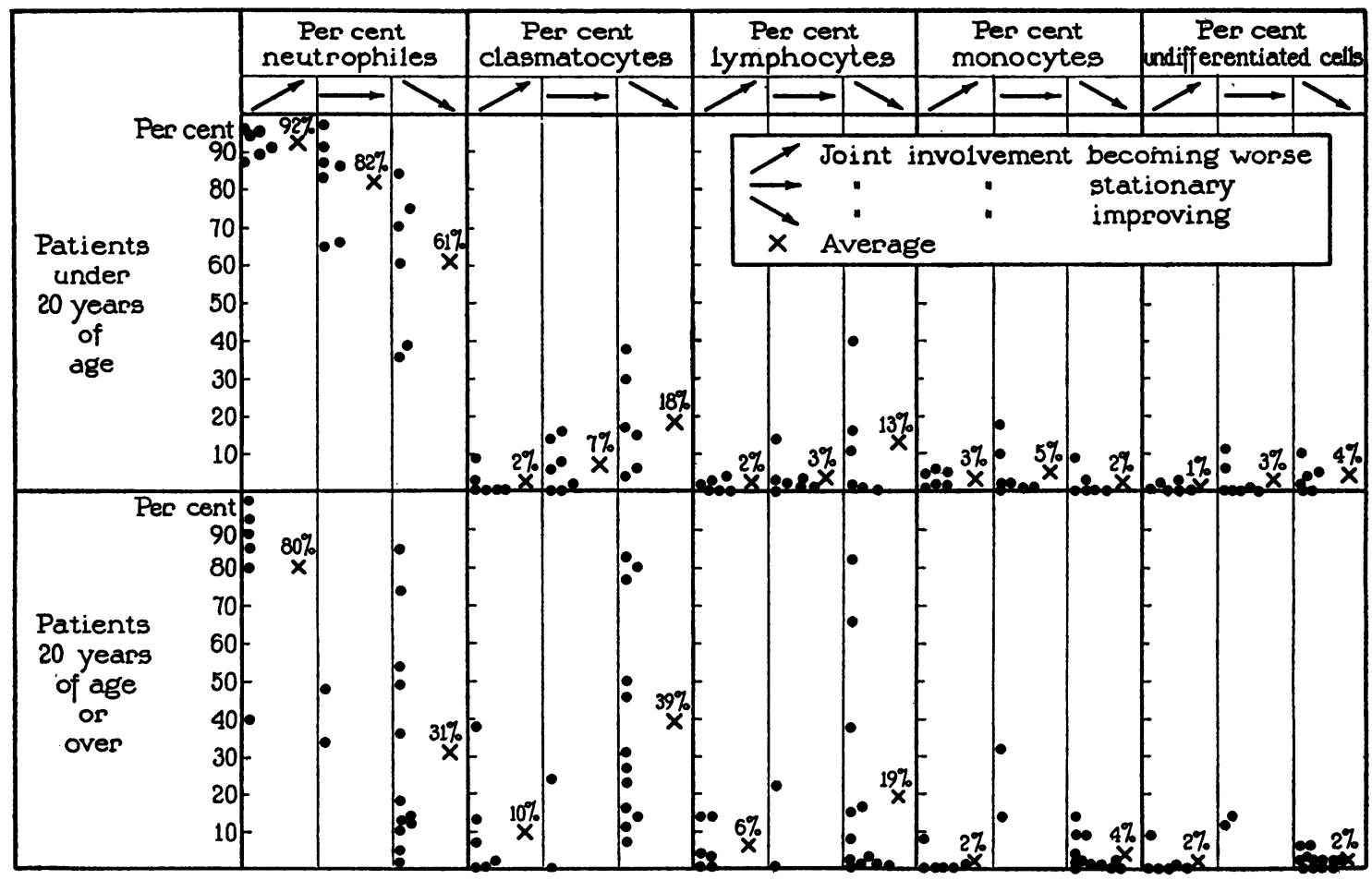

Fig. 8. Correlation between Stage of Arthritis and Differential formulas of White Cells in Synovial Fluid from Younger and Older Patients.

Each dot represents the finding for a given specimen of fluid.

surprising, there could be found no explanation for the apparent differences in the two age groups. One wonders, however, whether the latter may not be in some way related to the well known clinical differences often noted in rheumatic polyarthritis as it occurs in these two age groups.

The duration and severity of arthritis apparently had little bearing upon the type of cell predominant in the fluid other than that more of the early and severely involved joints tended to fall in the group showing an increasing severity of arthritis.

\section{Pleural and pericardial exudates from patients with rheumatic fever}

The findings in the 8 pleural and 5 pericardial exudates were essentially the same as those in synovial fluid. The total amounts of fluids were unknown, but in appearance they varied from clear to flaky. The total number of white cells varied from 1,600 to 12,400 per c.mm. with polymorphonuclear neutrophiles from 4 to 67 per cent, lymphocytes from 0 to 74 per cent, monocytes from 0 to 6 per cent, clasmatocytes from 4 to 74 per cent, undifferentiated young connective tissue cells from 0 to 7 per cent, and eosinophiles from 0 to 4 per cent. The most striking cytologic difference between these exudates and those from joints was the presence of 2 to 14 per cent of desquamated mesothelial cells in every sample. These cells, the characteristics of which in supravitally stained preparations have been described by others $(3,11)$, occurred singly or in groups of two to four, and were easily distinguished from all other types.

\section{Synovial fluid from non-inflamed human knee joints}

For comparison, it was desired to ascertain the number and types of cells present in the fluid of non-inflamed human joints. Samples were obtained from two normal knee joints and from three in which the only apparent abnormality was the presence of edema fluid. The first supposedly normal fluid was from a patient dying of cerebral hemorrhage, aspiration having been performed 
immediately postmortem. Approximately 0.5 cc. of clear, very mucoid fluid was obtained which contained 125 white cells per c.mm. as well as occasional erythrocytes. In supravitally stained preparations the differential count of 100 cells was as follows: polymorphonuclear neutrophiles, 27 per cent ; mature monocytes, 7 ; stimulated monocytes, 9 ; stimulated clasmatocytes, 8 ; undifferentiated young connective tissue cells, 12 ; synovial lining cells, 3 ; unidentified degenerated cells, 21 ; and indeterminate phagocytic cells, 13 . The latter, which have been described by Key (5), were obviously mature elements containing neutral red bodies of varying size and sometimes mitochondria; they could not be classified into monocytes and clasmatocytes, however, as they had characteristics of both. The other normal fluid was obtained from the hip joint of a six year old girl at operation for congenital dislocation of the hip. An approximate total count of 200 white cells per c.mm. was obtained with the following differential picture: polymorphonuclear neutrophiles, 7 per cent; monocytes, 5; stimulated clasmatocytes, 5 ; undifferentiated young connective tissue cells, 16; lymphocytes, 16; synovial lining cells, 7 ; and unidentified degenerated cells, 44 .

In general these findings are in accord with those of Key (5) and Bauer (6) for the synovial fluid of normal rabbits and cattle; however, in both these specimens the monocytes were fewer than was the case with the animals, and in the first case the polymorphonuclear neutrophiles were unexpectedly numerous. The large number of degenerated cells perhaps accounts for the comparatively few monocytes found, while Key's observation (5) that polymorphonuclear cells migrate into joint cavities shortly after death may explain the relatively numerous neutrophiles in Case 1. This count was done very soon after death, but the patient had been moribund for some hours before, and it is not unlikely that a migration of polymorphonuclears may have started.

The presence of synovial lining cells in these fluids in numbers comparable to those of normal rabbits and cattle was in contrast to their apparent absence from the arthritic exudates. Perhaps the small number of them normally desquamated in the latter were lost sight of in the great number of inflammatory cells. In the normal fluids they had the appearance described by Key $(5,15)$,
Bauer and his co-workers (6), and Forkner, Shands and Poston (3); granules or vacuoles staining with neutral red were never seen either in these specimens or in scrapings of normal human and rabbit synovial membranes.

Of the specimens from patients with non-rheumatic cardiac edema, one was aspirated during life and the other two immediately postmortem. The amounts obtained were $22 \mathrm{cc} ., 3 \mathrm{cc}$. and $8 \mathrm{cc}$. respectively. The white cells were so few that total counts were unsatisfactory and differential counts incomplete. In the first sample only two cells were seen after prolonged search : a small lymphocyte and a stimulated clasmatocyte. In the second, in addition to 9 erythrocytes, five cells were identified: two small lymphocytes, two stimulated monocytes, and a phagocytic clasmatocyte. In the third specimen, there were: one erythyrocyte, two unstimulated monocytes, and an indeterminate phagocytic cell. Taking into account the dilution by edema fluid, these figures are probably comparable to those reported for normal rabbits and cattle.

While no definite conclusions regarding the cellular content of non-inflammatory human synovial fluid can be drawn from so few samples, the results obtained do serve as a rough base line for observations upon the fluids from inflamed human joints.

\section{Joint exudates from patients with diseases other than rheumatic fever}

As controls, 25 exudates from joints of patients with diseases other than rheumatic fever were examined. Among these were: rheumatoid arthritis, ${ }^{2}$ 8; gonococcal arthritis, 3; syphilitic arthritis (infectious), 3 ; tuberculous arthritis, 2 ; purulent (hemolytic streptococcal) arthritis, 2 ; infectious arthritis of uncertain type, 5 ; and traumatic arthritis, 2. The results obtained are shown in Table III. The pus from the patients with purulent arthritis was, of course, unmistakable; in none of the other samples, however, was there any gross or cytologic characteristic which served to distinguish it from rheumatic exudates. In Shands' (8) study of synovial fluid from joints of patients

2 All these patients had arthritis of the type characterized by fusiform swelling of the proximal interphalangeal joints and ulnar deviation of the fingers. 
with infectious arthritis, the average percentages of lymphocytes and monocytes were higher than those obtained in the rheumatic exudates of the present series. On the other hand, individual synovial exudates of this series gave percentages of monocytes and lymphocytes considerably higher than the averages reported by Shands; so that cytologic examination of the synovial fluid is probably of little value in the differential diagnosis of individual cases.

The work of Sabin (13) and others would lead one to expect epithelioid cells and numerous monocytes in tuberculous arthritic exudates, and Geiger (14) has shown this to be the case in joint fluids from rabbits with experimental tuberculous arthritis. Contrary to expectation, however, the synovial exudates from two proven cases of early tuberculous arthritis, showed no epithelioid cells; and the monocytes, although more numerous than in the non-tuberculous exudates, had the customary appearance. In one other specimen, from a far advanced and caseous joint (not included in Table III), there were many degenerated polymorphonuclear neutrophiles and clasmatocytes but no epithelioid cells or monocytes. These results do not imply, of course, that epithelioid cells are not often present in exudates from tuberculous joints. Work is in progress to study this further.

\section{DISCUSSION}

Although it was not possible to follow the cytologic changes during the course of rheumatic arthritis in a single joint, the picture can, perhaps, be reconstructed from the results reported in the foregoing study. The primary response seemed to consist chiefly of polymorphonuclear neutrophiles with a few monocytes and undifferentiated young connective tissue cells. As recovery began, clasmatocytes increased in number and disposed of fibrin and degenerating cells by phagocytosis. In one patient with typical rheumatic fever (Sor., Table I), a small amount of fluid remained in one knee joint 72 days, and the synovial exudate, after this interval, contained 90 per cent of lymphocytes. This perhaps indicates that lymphocytes are the predominant cells in rare rheumatic exudates of such long duration, although Table I also shows that lymphocytes were occasianally numerous fairly early in the disease. The changes thus outlined are similar in many respects to those observed by Key (7) in synovial exudates of rabbits following injection of mild irritants into their joints. Such differences as exist may be due to the greater complexity of factors acting in rheumatic inflammation, as, for example, the tendency to relapse.

Finally, it is of interest to compare the cells of rheumatic granulomata and exudates. It had been suspected that exudates from patients with rheumatic fever might contain the characteristic cells of subcutaneous rheumatic nodules (1) and thus aid in the differential diagnosis of arthritis of uncertain type. This proved not to be the case, however, for no cells resembling those of the granulomata were seen in any exudate. In a previous study (1) it was concluded that the granuloma cells arise from undifferentiated connective tissue elements called by Maximow (16) primitive mesenchymal cells. Since the exudates likewise contained what were thought to be undifferentiated young connective tissue cells, a question arises concerning the relationship between them. In appearance they were entirely different: the granuloma cells showed neither mitochondria nor neutral red bodies and presented basophilic cytoplasm and very distinct cell membranes; the exudate cells, on the other hand, showed a general resemblance to young monocytes but with atypical and scanty mitochondria and neutral red bodies. Probably both types are closely related in origin, and it is suggested that their dissimilarities may be due to environmental differences and to continued development as fixed tissue elements in the one case but as wandering cells in the other. Certainly, the undifferentiated young connective tissue cells in the exudates here studied were in no way characteristic of rheumatic fever since they occurred equally in exudates from patients with other diseases. These observations are in keeping with Swift's (17) division of rheumatic manifestations into those chiefly proliferative and those primarily exudative, and coincide with the known pathologic changes of rheumatic fever; for numerous histologic studies have demonstrated that the proliferative lesions, as typified in the submiliary myocardial nodules and subcutaneous nodules, are composed of characteristic cells, but that the exudative lesions of joints, pleura and pericardium are, for the most part, cytologically non-specific. 


\section{SUM MARY}

The amount, character and cellular content of exudates from patients with rheumatic fever were studied in relation to certain clinical aspects of the disease and were compared with those of nonrheumatic exudates.

There was no obvious correlation between the amount of synovial fluid and the severity of arthritis; the number of cells per cubic millimeter ranged between 800 and 47,000 and the total number contained in the exudates tended to vary directly with the stage and severity of arthritis; the differential formula appeared to bear some direct relationship to the stage of arthritis and the age of the patient. Supravital stains revealed no cells similar to those previously described in rheumatic granulomata. Early there was a predominance of polymorphonuclear neutrophiles, with a few monocytes and undifferentiated young connective tissue cells; later there were numerous clasmatocytes containing debris and degenerating cells. Rheumatic pleural and pericardial exudates contained cells similar to those of the joints but with the addition of a few mesothelial elements. Because non-rheumatic exudates were similar in microscopic content, no specific character could be assigned to exudates in rheumatic fever.

\section{BIBLIOGRAPHY}

1. McEwen, C., Cytologic studies on rheumatic fever. I. The characteristic cell of the rheumatic granuloma. J. Exper. Med., 1932, 55, 745.

2. Sabin, F. R., Studies of living human blood cells. Bull. Johns Hopkins Hosp., 1923, 34, 277.

3. Forkner, C. E., Shands, A. R., and Poston, M. A.,
Synovial fluid in chronic arthritis-bacteriology and cytology. Arch. Int. Med., 1928, 42, 675.

4. Forkner, C. E., The synovial fluid in health and disease with special reference to arthritis. J. Lab. and Clin. Med., 1930, 15, 1187.

5. Key, J. A., Cytology of the synovial fluid of normal joints. Anat. Rec., 1928, 40, 193.

6. Bauer, W., Bennett, G. A., Marble, A., and Claflin, D., Observations on normal synovial fluid of cattle. I. The cellular constituents and nitrogen content. J. Exper. Med., 1930, 52, 835.

7. Key, J. A., Experimental arthritis. The reaction of joints to mild irritants. J. Bone and Joint Surg., 1929, 11, 705.

8. Shands, A. R., Synovial fluid in infectious and neuropathic arthritis. South. M. J., 1930, 23, 818.

9. Hitchcock, C. H., and Ehrich, W., A new method for differential staining of plasma cells and of other basophilic cells. Arch. Path., 1930, 9, 625.

10. Forkner, C. E., The origin and fate of two types of multinucleated giant cells in the circulating blood. J. Exper. Med., 1930, 52, 279.

11. Sabin, F. R., Doan, C. A., and Cunningham, R. S., Discrimination of two types of phagocytic cells in the connective tissues by the supravital technique. Carnegie Institution of Washington, Pub. 361, Contributions to Embryology, No. 82, 1925, 16, 125.

12. Kling, D. H., Erythroblasts and myelocytes in traumatic effusions of the knee joint; their significance for the diagnosis of intra-articular fractures. Am. J. Surg., 1929, 7, 824.

13. Sabin, F. R., Cellular studies in tuberculosis. Am. Rev. Tuberc., 1932, 25, 153.

14. Geiger, J. T., Personal communication.

15. Key, J. A., The synovial membrane of joints and bursae. In Special Cytology, edited by E. V. Cowdry, Paul B. Hoeber, New York, 1928, 2d ed., p. 1055.

16. Maximow, A. A., and Bloom, W., A Text-Book of Histology. W. B. Saunders, Philadelphia, 1930, p. 77.

17. Swift, H. F., Rheumatic fever. Am. J. M. Sc., 1925, 170, 631 . 